\title{
A Tale of Three Discourses: The Dominant, the Strategic and the Marginalized*
}

\section{Loizos Heracleous}

Oxford University

ABSTRACT This study drew from a structurational view of discourse and employed a discourse analysis approach based on rhetoric and hermeneutics to analyse the organizational discourses operating in the UK operations of a global human resources consulting firm, People Associates. The aims were firstly to understand in what sense we can speak of 'modes of discourse' in organizational settings; secondly to explore the potential existence and nature of interrelations among different modes of discourse; and thirdly to explore the constructive potential of modes of discourse on their social and organizational contexts. The results suggest that modes of discourse can usefully be seen as rhetorical enthymemes constituted of relatively stable, normative structures and flexible, action-oriented structures; that modes of discourse can interrelate through their deeper structural features, and can have mutually co-optive or antagonistic relationships; and lastly that the constructive potential of discourse is based primarily on its deeper structures, and on the consonance of surface communicative actions with these structures. This research thus sheds light on fundamental definitional and substantive issues in organizational discourse; in particular offering a novel conceptualization of the nature of discourse, a further understanding of discursive interrelations, and finally one way to understand its constructive effects on social organizations.

\section{INTRODUCTION}

This study employs a structurational view of discourse and a discourse analysis approach based on rhetoric and hermeneutics to analyse the discourses operating in the UK sites of People Associates (PA), a global human resources consulting firm, in the context of PA's organizational change programme. The aims of analysing PA's discourse were threefold. Firstly, to understand in what sense we can speak of 'modes of discourse' (Giddens, 1984, p. 33) in organizational settings. Secondly, to explore the potential existence and nature of interrelations among different modes of discourse. Thirdly, to explore the constructive potential of Oxford University, Oxford OX1 5NY, UK (loizos.heracleous@templeton.ox.ac.uk). 
modes of discourse in their social and organizational context. In aiming to shed light on the above questions, this research responds to calls for greater clarity in the specification of the concept of discourse, as well as a deeper understanding of the constructive effects of discourse in social organizations (Grant et al., 2001; Keenoy et al., 1997; van Dijk, 1997).

Three modes of discourse were revealed: the dominant discourse, the strategic change discourse and the marginalized counter-discourse. The dominant discourse is patterned in terms of enthymeme structures (rhetorical structures of argumentation that draw from the premises already held by the audience in particular social contexts) that possess both normative and positive, action-oriented, elements. The strategic change discourse draws its legitimacy by being located in the structures and constructions of the dominant discourse, exhibiting a co-optive relationship with the dominant discourse. The counter-discourse, on the other hand, bears an antagonistic relationship with the dominant discourse. It is patterned by what it opposes, but its opposition is weak and impotent in influencing its social and organizational context. These three modes can be expressed as rhetorical enthymemes constituted of both relatively stable normative structures and flexible action-oriented structures. The results suggest that the constructive potential of discourse is based primarily on its deeper structures, and on the consonance of surface communicative actions with these structures.

\section{A Structurational View of Discourse}

Giddens' structuration theory has had a significant and growing influence in organizational research (e.g. Barley and Tolbert, 1997; Weaver and Gioia, 1994). Giddens' work has striven to transcend persistent dualisms in social theory, especially that of structure and action. His notion of the 'duality of structure' in particular sensitizes us to the fact that structural aspects of social systems are not separate from agents' action as often conceptualized, but are integral to action, being both its medium and the outcome (Giddens, 1993). From this perspective daily practices (including communicative actions) are manifestations of deeper structures of signification, domination and legitimation. Structures are thus instantiated, reproduced and can potentially be changed through daily practices (Giddens, 1984, p. 36).

Drawing an analogy with social systems, discourses can also be seen as exhibiting structural properties that according to Heracleous and Hendry (2000) are largely implicit, inter-textual, trans-temporal and trans-situational. These properties are manifested, instantiated or challenged in daily communicative actions. Drawing from Heracleous and Barrett (2001), this research thus adopts a view of discourse as a duality that is constituted by two dynamically interrelated levels: the surface level of communicative actions, and the deeper level of discursive structures, recursively linked through the modality of actors' interpretive schemes.

(C) Blackwell Publishing Ltd 2006 
At the level of communicative action, discourse is constituted of communicative statements that occur in the process of social interaction. Agents can pursue their perceived interests, construct shared perspectives and build interpersonal relations, as well as express subjective experiences through communicative action. These broad types of aims, that Habermas (1984) has identified respectively with the teleological, normative and dramaturgical models of action, come together in his encompassing 'communicative model of action' (Habermas, 1984, pp. 94-6). In this sense discourses have a pragmatic dimension; they not only say things, but also do things (Austin, 1961; Oswick et al., 1997).

Discursive deep structures on the other hand are quite stable, mostly implicit, and continually recurring processes and patterns that underlay and guide surface, observable events and actions (Heracleous and Barrett, 2001). Discursive deep structures are persistent features of discourse that transcend individual texts, speakers or authors, situational contexts and communicative actions and pervade bodies of communicative action as a whole and in the long term (Heracleous and Hendry, 2000). This study operationalizes discursive structures as rhetorical strategies actualised through rhetorical enthymemes, or argumentations-in-action.

Discursive deep structures should be understood in a structurational and not a structuralist sense. In structuralist approaches such as Foucault's (1972) archaeology, subjects' actions, identities, and even their reason are said to be determined by pervasive discursive structures (Jacobs and Heracleous, 2001). From a structurational viewpoint, however, the various types of structures are seen as the rules and resources that actors draw on and enact in their daily practices; and which have no other existence than their instantiation in action, and in agents' interpretive schemes. Social structures and the discursive structures they are linked to, are thus not separate from and determinative of human actions, but are both the medium and the outcome of such actions (Giddens, 1984).

\section{FIELD RESEARGH AND DISGOURSE ANALYSIS APPROAGH}

\section{Field Research}

In early 1994 I set out to study the role of organizational discourse(s) in the context of organizational change. I collected the empirical data reported here between June 1994 to March 1996. I also conducted retrospective data gathering that focused on the organization's history and critical incidents, going back to the organization's founding in the UK in 1963. The philosophical commitments guiding the research programme centred on interpretivism, the conviction that accounts of social life must consider the actors' frame of reference and be adequate at this level of first-order meaning; and on a view of reality as inter-subjective and socially constructed (Berger and Luckmann, 1966).

I employed the methodological paradigm of ethnography with an action research or 'clinical' element. My role approximated what Schein (1987a) calls 
'the ethnographer as clinician'. I partly acted as a clinician because I was allowed access to the organization on the assumption that my involvement would 'add value' to the organization change programme under way. In this capacity I offered periodic feedback to senior management regarding actors' views on the change process and any specific issues that actors brought up in this connection; with the understanding that management could employ this feedback in managing change in the organization. The incorporation of a clinical element can enable the clinician to be taken 'behind the scenes' by senior managers who seek advice, but could also constrain data collection from lower levels of the organization who perceive the clinician as an instrument of management, or 'one of them' (Schein, 1987b). In this case, however, being perceived as a clinician in a clinicians' land proved to be an important facilitating factor in data collection from all levels of the organization.

Given the commitment to understanding the natives' frames of meaning (Geertz, 1973), I employed the research strategy of a longitudinal case study (Eisenhardt, 1989). After initial correspondence with the company enquiring about long-term access for the study, I was invited to its London headquarters for two separate interviews with senior management, after which I was granted access. Within the strategy of a longitudinal case study, I used the methods of in-depth interviewing, participant and non-participant observation, cultural audits through focus group sessions, use of informants, periodic descriptive surveys and document analysis. I conducted a total of 104 interviews involving consultants, surveys and IT staff, support staff, and past leaders of People Associates. I triangulated the data within and across methods, in order to increase the internal validity of the findings and to discover within or between-method divergences or convergences that could lead to new lines of inquiry. After I discerned the main cultural values and beliefs of the organization, my findings were circulated to all employees, who widely judged them to be representative of their organization, a key validating criterion of ethnographic research (Hammersley and Atkinson, 1995).

My initial analytical task was to detect patterns and processes which could help to 'make sense of what is going on in the scenes documented by the data' (Hammersley and Atkinson, 1995, pp. 209-10). I was conscious throughout the research programme of what Giddens (1993) calls the 'double hermeneutic' in social science, and Van Maanen (1979) 'first and second-order concepts' in ethnography, aiming to align my understanding with the first-order concepts of the agents involved. In addition, I did not take individual fragments of data as indicative of cultural features, but interpreted them as part of a wider corpus of data. The data analysis was characterized by a hermeneutic, iterative process of going back and forth from critical reflection to the data, and from part to whole, searching for key themes and patterns, and questioning, redefining or buttressing with further evidence the themes and patterns identified (de Vries and Miller, 1987; Thachankary, 1992).

C Blackwell Publishing Ltd 2006 


\section{Discourse Analysis Approach}

The discourse analysis approach employed here draws from the field of rhetoric (Aristotle, 1991; Gill and Whedbee, 1997) within the context of a hermeneutic orientation (Giddens, 1979, 1987; Ricoeur, 1971a, 1971b, 1973a, 1973b, 1983, 1997). Discourse analysis approaches have often not paid sufficient attention to textual context and temporality (Cicourel, 1981; Fairclough, 1992). In this study rhetoric and hermeneutics are drawn on to develop a discourse analysis approach informed by interpretivism and which views discourse and its context as mutually implicated.

Rhetoric and hermeneutics share close historical and conceptual linkages as well as a constructive view of language (Berger and Luckmann, 1966; Palmer, 1969). Rhetoric originally included the domains of moral education, philology and interpretation of classical texts (Palmer, 1997). Principles of textual interpretation were then transferred from rhetoric to hermeneutics during the Renaissance, when rhetoric encompassed not only the ars bene dicendi - the art of speaking well, but also the ars bene legendi - the art of reading well (Gadamer, 1997; emphasis in original).

Hermeneutic analysis. The earliest usage of the term hermeneutics referred to principles of biblical interpretation, but this was subsequently broadened to refer to general rules of philological exegesis. Hermeneutics involves both the task of textual interpretation as well as the reflexive concern with the nature of understanding and interpretation itself (Palmer, 1969). Ricoeur has defined hermeneutics broadly as the 'art of interpreting texts' (Ricoeur, 1973a, 1997, p. 66), posing as a fundamental concern the fact that once discourse is inscribed as 'text', it is severed from its author and its meaning as interpreted by new audiences may not necessarily coincide with the author's original intentions (Ricoeur, 1971b, 1973b). There may be several interpretations of texts depending on readers' preunderstandings (or interpretive schemes) and their particular interpretations of a text in relation to their own perceived situation (Ricoeur, 1983).

A key insight in hermeneutics is that meaning does not reside solely in the text but is conditioned by its context, and the perceptions of the agents within that context (Palmer, 1969). Acknowledging the possibility of various textual interpretations, however, does not necessitate a lapse to relativism, the resignation to the idea that there is no way to arrive at certain textual interpretations that are more valid than others (Phillips and Brown, 1993). For Ricoeur (197 1a), for example, a text displays a limited field of potential interpretations as opposed to being a repository of potentially unlimited meanings. In line with this view, Giddens suggests that the interpretive validity of texts can be improved through ethnographic inquiry in the settings of production of the text, the intellectual resources the author has drawn on, the characteristics of the audience it is addressed to, the author's or speaker's intentions as well as the practical knowledge involved in writing or speaking with a certain style for a particular audience (Giddens, 1979, p. 43; 1987, p. 106). 
In this research I approached texts as collections of communicative actions fixed in writing, and analysed interview transcripts, published documents and observations as texts. I employed inter-textual analysis, aiming to identify central themes in and across texts, explored the existence and extent of thematic unity (how central themes are interrelated in broader argumentations both within texts and intertextually), and searched for patterns in textual and ethnographic data over time (Barry and Elmes, 1997; de Vries and Miller, 1987; Thachankary, 1992).

Rhetorical analysis and rhetorical enthymemes. Rhetorical analysis is versatile, being able to engage with several areas including the situation, audience, credibility of the rhetor, rhetorical styles, genres that rhetorical texts are part of, use of tropes, or how everyday talk can in fact be rhetorical. This occurs through the use of certain ideas but not others, through the particular implications and connotations of the ideas used, through the construction of certain kinds of subjects, and through what the 'frame' evoked by the ideas used highlights or excludes (Gill and Whedbee, 1997; Gowler and Legge, 1983).

My aim was to identify the rhetorical strategies that actors have consciously or unconsciously used consistently in PA. These rhetorical strategies act as structural features of discourse, and can be discerned through the analysis of communicative actions of various speakers/authors, discussing various issues in different situational and temporal contexts. These rhetorical strategies most often take the form of enthymemes, or argumentations-in-use. These enthymemes are not necessarily consciously evoked, being located in actors' practical consciousness (Giddens, 1984).

Enthymemes are rhetorical structures of argumentation. Traditionally, 'whereas the syllogism was the most prominent form of logical demonstration, the enthymeme was its rhetorical counterpart. Enthymemes were thought of as syllogisms whose premises are drawn from the audience. They are usually only partially expressed, their logic being completed by the audience' (Eemeren et al., 1997, p. 213). Enthymemes, therefore, are not universally rational or true, but are so only within specific socio-cultural contexts, depending on their conformity to the audience's existing beliefs and assumptions (Cheney et al., 2004). One way researchers can uncover taken for granted values and beliefs within particular contexts is through identification and analysis of enthymemes, and particularly their unstated and assumed premises (Gill and Whedbee, 1997). These values and beliefs can be seen as structures of legitimation that underlie agents' interpretations and (communicative) actions (Giddens, 1984, 1993).

Enthymemes whose premises are inculcated in agents in particular organizational contexts have been labelled 'enthymeme 2', as opposed to 'enthymeme 1' where the premises are drawn from broader societal and cultural contexts (Tompkins and Cheney, 1985); even though it would be difficult to distinguish neatly between these in practice. In line with an interpretive view of organizational 
discourse, enthymemes have an important constitutive role in organizations, influencing agents' interpretations and actions (Cheney and McMillan, 1990; Cheney et al., 2004). Thus I treated the research site as a 'field of institutionalized discourse' (Cheney and McMillan, 1990, p. 103) and endeavoured to discover these institutionalized features that I operationalized as organizational enthymemes.

In order to identify enthymemes in People Associates, I first searched for central textual themes. I explored individual texts for central themes that were explicitly stated or assumed, and then compared the results inter-textually to discover themes that transcended individual texts and were present in several texts deriving from diverse sources and produced in different situations. I then analysed the interconnections among these central themes, and their functions in structures of argumentation. I then combined the findings of the first two steps to determine enthymeme structures, following Fisher (1988). I lastly conducted inter-textual analysis, relating findings from single texts across several texts, moving from the single texts to the broader discourses and vice versa. Throughout the process I utilized ethnographic data both as a resource for enriching textual interpretation, and as a form of triangulation with the textual data, in order to improve the validity of textual interpretation, and of the enthymeme structures structuring these texts.

The next section presents an analysis of the discourses of People Associates. This analysis aims firstly to offer a deeper understanding of the nature of 'modes of discourse' (Giddens, 1984, p. 33) in organizational settings; secondly to explore the potential existence and nature of interrelations among different modes of discourse within organizations; and lastly, to explore the constructive potential of modes of discourse in their social and organizational context.

\section{FIELD ANALYSIS: DISGOURSES OF PEOPLE ASSOGIATES}

\section{Context: Central Values and Beliefs of People Associates}

Interviews with past leaders and document analysis indicated that People Associates' early growth was characterized by conditions fostering the development of 'thick' cultures. These conditions include a long history and stable membership, absence of institutional alternatives, and frequent interaction among members (Wilkins and Ouchi, 1983). Key features of PA's culture included a strong client orientation, a perception that the 'core business' of the firm was job evaluation, and also high individualism and autonomy of consultants. The mythology of the organization was replete with the figures of 'lone rangers' and 'guidechart jockeys' who would individually ride in client organizations, conduct the job efficiently and help to achieve record annual sales for the consulting firm. The organizational structure was loose, and subject to continuous incremental changes called the 'autumn manoeuvres' in the organizational vocabulary, that did not pose a challenge to entrenched values and beliefs. 
Although there are other subcultures in PA (the support staff and survey department's subcultures), it is the consultants' sub-culture that dominates. Its importance is indicated by the high number of its members, its potent influence on organizational decisions and actions, and its strong internal homogeneity. In terms of membership numbers, over two thirds of PA's employees are consultants, and many of the around one fifth of employees who work in the survey/IT departments aspire to becoming consultants in the longer term, as ethnographic data have shown. In terms of influence on decisions and actions, leaders of the consulting subculture determine People Associates' strategic direction and most internal organizational arrangements. Lastly, in terms of homogeneity of the dominant consulting sub-culture, data on the recruitment process, observation of behaviours, and in-depth interviews indicated a highly homogeneous body of consultants. When interviewing new recruits and asking for surprising or puzzling features of PA (Schein, 1992), many marvelled at how 'everybody is so much like me'.

\section{The Dominant Discourse}

I analysed several texts in PA such as transcribed interviews, internal memorandums, reports of project groups, company publications, and Christmas speeches over a five-year period (1991-95) prepared and delivered by three different MDs. Two discursive central themes were discerned: success, or another variant such as being number 1 , and clients. Success was constructed financially, and adding value to clients was seen as the means of achieving success. These central themes were involved in implicit and more explicit enthymematic structures, in which they functioned as goals or as means. These central themes are part of an overall rhetorical strategy characterized by primary and secondary argument structures that fulfil normative and positive functions in their organizational context.

The core enthymeme identified takes a form of an argument where two premises jointly support a conclusion (P1 and P2 lead to $\mathrm{C} 1)$. This conclusion (C1) then becomes the first premise $\left(\mathrm{P}^{\prime}\right)$ of a sub-enthymeme which, jointly with a second premise (P2') supports a second conclusion (C2). Table I shows the core enthymeme structure identified, the main discursive manifestation of each element, and an explanation of the nature of each statement.

The structurational view of discourse provides the theoretical grounding for this enthymeme pattern. P1 and P2 represent persistent deep structures of agents' discourses; these are the implicit, taken for granted, and usually unstated premises, acting as entrenched structures of legitimation in specific social contexts. These deep structures are continuously manifested in agents' (communicative) actions, residing in agents' 'practical consciousness' (Giddens, 1984). Their main function is normative, acting to support or rebuke action-oriented argumentations which are more explicitly articulated in communicative actions (represented by $\mathrm{P}^{\prime}$, $\mathrm{P} 2^{\prime}$ and C2). The content of $\mathrm{P}^{\prime}$ and $\mathrm{C} 2$ is variable and can shift according to the 
TABLE I. Core enthymeme structure of the dominant discourse

\begin{tabular}{|c|c|c|c|c|}
\hline \multirow[t]{2}{*}{ Enthymeme structure } & \multicolumn{2}{|c|}{ Discursive manifestation } & \multicolumn{2}{|c|}{ Nature of statement } \\
\hline & $P 1$ & Our key goal is $\mathrm{X}$ & $\mathrm{P} 1$ & $\begin{array}{l}\text { Value stating desirable } \\
\text { state of affairs }\end{array}$ \\
\hline $\mathbf{P 1}+\mathbf{P 2}$ & $P 2$ & Y leads to $\mathrm{X}$ & $\mathrm{P} 2$ & $\begin{array}{l}\text { General belief of } \\
\text { contingent relationship } \\
\text { in normative domain }\end{array}$ \\
\hline $\mathbf{C} 1 \rightarrow \mathbf{P 1}^{\prime}+\mathbf{P}^{\prime}$ & $\mathrm{C} 1 \rightarrow \mathrm{P} 1^{\prime}$ & $\begin{array}{l}\text { Therefore, we need to } \\
\text { take appropriate action } \\
\text { to achieve Y }\end{array}$ & $\mathrm{Cl} \rightarrow \mathrm{Pl}^{\prime}$ & $\begin{array}{l}\text { General conclusion on } \\
\text { required type or class } \\
\text { of action }\end{array}$ \\
\hline C22 & $\mathrm{P} 2^{\prime}$ & Action $\mathrm{Z}$ leads to $\mathrm{Y}$ & $\mathrm{P} 2^{\prime}$ & $\begin{array}{l}\text { Belief of contingent } \\
\text { relationship in the } \\
\text { action-oriented domain }\end{array}$ \\
\hline & $\mathrm{C} 2$ & $\begin{array}{l}\text { Therefore, we need to do } \\
\text { Z }\end{array}$ & $\mathrm{C} 2$ & $\begin{array}{l}\text { Con clusion of required } \\
\text { specific action to be } \\
\text { taken }\end{array}$ \\
\hline
\end{tabular}

situation. The communicative level enthymeme structures are thus both flexible in terms of content, but also patterned and entrenched in deeper discursive structures. These function as structures of legitimation that are highly influential on actors' interpretations and actions. Analysis of PA's discourse indicated that $\mathrm{X}$ is the central themes of success (constructed financially), $\mathrm{Y}$ is the central theme of adding value to clients, and undertaking strategic change was the situational exigency that took the place of the flexible theme $\mathrm{Z}$.

The central themes of success and clients, interrelated in a means/end relationship, dominated all the Christmas speeches given by PA's MDs over a five-year period. Such speeches are highly symbolic as they are delivered to the whole organization in a context where the MD recounts what is truly important to them and the organization. In addition, they are not for outside consumption, so comments aimed at managing the organization's image with outside stakeholders are helpfully absent from these speeches. In PA's case, three different MDs were involved over this period, which increases the validity of inter-textual findings, as the texts did not originate from the same person and at the same time, but in a sense from the 'collective consciousness' of the highest levels of the organization.

Several other texts displayed the above themes. For example, the following is an extract from a report to senior management prepared in 1995 by the 'expertise working group' which was charged with reviewing consultants' expertise development process and was led by a senior partner who was also a member of senior management. The extract below is a key part of the document as it in effect contains the legitimatory statement as to why managerial and consulting attention and scarce organizational resources should be diverted from other areas to the expertise area. 
The purpose of the expertise area is to help grow the business:

- In the long term by developing client solutions which are not easily replicable by competitors and which represent value added to the client and therefore good margins for PA.

- In the short term/medium term by developing and upgrading client solutions and equipping/enabling consultants to sell and deliver.

The ultimate test of success will be for PA Consultants:

- Does it help me sell more?

- At value added prices?

This textual fragment is a microcosm of the dominant discourse's enthymeme structures, central themes and their constructions: Firstly, 'success' ('the ultimate test of success . ..') is matter-of-factly placed as the ultimate objective of the whole endeavour. Secondly, 'success' is constructed financially both for individual consultants ('does it help me sell more?') as well as for the organization ('the purpose of the expertise area is to help grow the business'). Thirdly, 'clients' are seen as the means to this success ('in the long term by developing client solutions . . . in the short term/medium term by developing and upgrading client solutions...'). Fourthly, the expertise project, the surface theme of this textual fragment, occupies the place of $\mathrm{Z}$ in the secondary structure. This is flexible enough so that matters relating situational exigencies (the positive order) are located in it and legitimated by reference to the primary structure (the normative order).

A telling indication of the importance of the central themes of clients and success, and specifically financial constructions of success, could be seen in the organization's reward and evaluation system. This is a key organizational process in that it indicates what an organization values and what agents should attribute importance to. Interviews showed that consultants overwhelmingly believed that their success and promotion in PA was determined by whether they achieved their billing and sales targets. For example, a widespread view among consultants was that:

... at the end of the day I think that PA will place more emphasis on meeting the targets than anything else. . . I believe that my evaluation for the last year was based 100 per cent on the extent to which I met my billing target, regardless of any circumstances which impacted on my ability to meet this target.

Referring to PA's efforts to broaden the evaluation criteria, another consultant expressed the broadly held view that:

The performance management process is still very numbers driven. I mean, there's been a lot of talk about moving away from that, and the competency 
framework is useful in focusing more on behaviours, than just on numbers, just on outputs, but at the end of the day, you don't hit the numbers, you don't get a decent appraisal, irrespective ...

Targets were set at a very challenging level. Sales targets depended on one's seniority, with more senior people having higher sales targets. Billing targets on the other hand were similar across the hierarchical spectrum, generally set at 185 days per year. Excluding weekends and holidays, this did not leave much time to develop client relationships, develop project proposals, sell projects, and carry them out; all while trying to develop one's expertise. This caused high levels of stress to consultants who knew that if they missed their targets for two years in a row, their job was at risk. To highlight this point, some consultants mentioned the example of colleagues returning to work after being sick, without having made a full recovery, because they were concerned about meeting their targets. In turn PA's focus on billing and sales targets led to zealous guarding of one's client list, which constituted a potent power base in PA, a means by which one's success in the organization was attainable and sustainable.

In interviews, consultants reiterated how important it was to develop one's internal network, so that one would be invited to participate in delivering projects to clients. The widely held view was that 'it's down to who you know and how you manage your network'. PA exhibited an internal market in this regard, and it was up to consultants to 'sell' their skills and convince their colleagues that they could indeed deliver to a high level of reliability and quality. According to a consultant,

The other thing which is different from other companies is the sort of internal market... where you're basically selling yourself to your colleagues to get involved in a project. ... Lots of freedom, but you're sort of, you name your price. . . . If I wanted to do something, if I'm desperately short of work I could price myself at half the time and am actually encouraged to do so in order to just get the numbers up.

It was particularly crucial for new consultants to develop their internal network and to be 'taken under the wing' of a more senior person. One new consultant showed me her personal 'positioning' diagram that she had developed and subsequently updated, that portrayed her particular consulting skills in relation to PA's 'organizational effectiveness' consulting practice. In effect she had developed a visual representation that positioned her specific skills vividly in the broader context of PA's offerings, so as to improve the visibility and memorability of her position in PA's competitive internal market of consulting talent.

Thus PA's reward and evaluation system, and the related operation of the internal market, can be seen as a further microcosm of the discursive central themes of PA; the importance of clients as a means of reaching financial success, not 
only for the organization as a whole but also for individual consultants. Access to clients was determined by one's success in building their internal network, as well as by their existing client list, which was a potent source of power in PA. These organizational processes (reward and evaluation system and the internal market) ensured that the discursive central themes of clients and success penetrated both the agential and by extension the organizational levels, perpetuating their continuous reproduction through their recursive effects at the level of interaction.

Vivid examples of the effects on agents' action was consultants placing high priority to client demands above all else, sometimes neglecting their own expertise development, being possessive about their client list, and often treating support staff abruptly and insensitively.

With regard to expertise development, an interesting example of the importance of clients is found in the following memo, sent by a senior director to the MD in 1994:

\section{Consultant Training}

Dropping out of booked courses because of client meetings/client pressures has once again become accepted practice. Consultants are treating course attendance as optional, and are:

1. Failing to meet their own development objectives.

2. Letting down their colleagues on the course.

3. Abusing the time of tutors who are also under client pressures.

If we can't manage this through the expressed values I suggest we do so through the measurement system.

How about?

1. People won't be accredited if they don't do the training. Then they won't be able to do the work.

2. If people cancel at less than a week's notice because of client commitments they can go to their commitment, but the billing goes to the tutor.

This example was a suggested remedy to what was seen as a growing problem, consultants placing their commitments with clients above the most important internal process in a knowledge organization, their own expertise development. A representative view in PA was, according to a consultant, "if a client says "jump", you jump!'

The importance of adding value to clients as a key legitimating factor for consultants' actions or inactions is illustrated by the following incident I observed 
in the corridors of PA's headquarters: Two female consultants, one a new recruit and the other an experienced principal consultant met in the corridor. They had a short, friendly chat around work issues. At one point the principal consultant asked why the new consultant had not attended a meeting with a certain client which had taken place a couple of days earlier. The new consultant replied that she didn't think that she could have added value, since she did not have experience in the particular topic of the meeting. The principal then replied that she would have actually added value if she had attended since she could have given a fresh perspective to the situation. This incident can be seen as a typical manifestation of the overall pattern, where the new consultant's inaction is placed as $\mathrm{Z}$ in a variant form of the secondary enthymeme pattern:

P1: We need to do what it takes to enable value-delivery to clients (implicit premise).

P2: My going along to the meeting would not have enabled this because I don't have enough experience in the topic of the meeting.

C: Therefore I didn't go.

The principal consultant's counter-argument can be stated as follows:

P1: We need to do what it takes to enable value-delivery to clients (implicit premise).

P2: Your coming along to the meeting would have enabled value-delivery to the client because we would have had the benefit of a fresh perspective on the topic.

C: Therefore, you should have come along to the meeting.

Both the argument and the counter-argument are acceptable in that social context because they are legitimated at a higher level by the primary structure, where adding value to clients is the means to reach the ultimate goal, financial success.

A further example of the importance of clients, and the impact of this focus on support staff in PA, is the first one-day orientation programme for support staff held during March 1995, which I observed. This programme was set up partly as a result of my feedback to the organization that support staff did not feel adequately familiar with PA's client offerings and how they contributed to them. The afternoon session was structured as a 'trial' of an imaginary PA consultant. The charge, coined by a senior director, was: 
that the defendant, a PA consultant, treated support staff in a way that failed to use their time effectively or showed respect for them and their skills, thus preventing PA from giving best service to our clients.

The judge, the counsels for both sides and the jury were all secretaries; there was no doubt of the verdict. The defence of the consultant was half-hearted, the prosecution strong, and the deliberation of the jury unusually short and unanimous.

A key revealing aspect of the mock trial from a discourse analysis perspective is firstly the nature of the charge, and secondly, how it was legitimated. The charge was derived from my earlier feedback to senior management, based on interviews with support staff, that they generally felt unvalued and unhappy with the way many consultants treated them. The legitimation of the charge, importantly, was based on 'preventing PA from giving best service to our clients', as opposed to several other possible legitimating factors (for example that some consultants' inconsiderate behaviour caused mental distress to support staff, or that it is ethically wrong to mistreat people).

The enthymeme and central themes discussed above constitute PA's dominant discourse in at least three senses: Firstly, in terms of legitimatory power; if one's arguments and opinions are to be taken seriously by those in power, they must draw on the discursive structures and constructions discussed above. Secondly, in terms of fixing of spoken discourse as text; the overwhelming majority of written communications in PA exhibit this discourse. Thirdly, in terms of diffusion; the majority of organizational members (consultants, surveys and IT staff, and some support staff) articulate their task-related thoughts and opinions in terms of this discourse.

\section{The Strategic Change Discourse}

I defined PA's strategic change discourse as the general body of texts that addressed the various issues related to the change process. Such texts included initial memorandums among senior directors about the need for change, the outcomes of planning sessions, handouts at employee consultation meetings and internal organization change bulletins. The analysis of this body of texts did not focus on such surface issues as the specifics of the structural change, implementation details, or who would be responsible for what, but on the legitimatory statements for the change and its aims. This is a methodological direction arising from Giddens' (1993, p. 92) discussion of the rationalization of conduct as a 'basic feature of the monitoring intrinsic to the reflexive behavior of human actors as purposive beings'. To understand these rationalizations I thus focused on textual fragments that displayed them.

Strategic thinking at the communicative level. At the surface communicative level, initial texts about the strategic change process were concerned with the long-term direction, structure and processes of the organization. For example, initial internal 
memorandums among senior management discussed PA's evolution from a single product/service organization to portfolio integration; then the alignment of this portfolio with business strategy; the organizational implications of these shifts; and the critical success factors for sustaining this journey. A second focus for discussion was the changing patterns of PA's various consulting offerings, relating these to market trends and requirements, making strategic recommendations as to where PA should focus in future, and arguing for the need for radical change. Lastly, texts focused on defining a vision and mission for the future, defining the main organizational changes required to arrive to that, the particular competitive advantages that PA should strive to achieve, the main internal processes that needed to be focused on, and the management of PA's image in the marketplace.

The outcome of these dialogues was that PA had to aim for cultural change (especially a shift away from individualism to teamwork); substantial growth in size through more intensive recruitment of consultants and selling of larger consulting projects; a more focused client relationship management process to increase the efficiency of consulting effort; increased breadth and depth of consultants' expertise; and integration of various distinct consulting methodologies.

As the intended strategic direction became clearer, later texts focused on more operational issues such as the required organizational design through business process mapping, critical success factors both for PA and for achieving the change, the responsibilities and membership of the change steering group and the change teams, action timetables, and the progress achieved over time.

The structural level of the strategic change discourse - focus on success. Despite this diversity of content at the communicative level, at the structural level almost all internal communications posed explicitly or implied that success was the ultimate objective of, and legitimating factor for, the strategic change programme. For example, statements such as 'What underpins our success?' and 'What are the factors most critical in sustaining the transformation, in the right direction and to achieve success?' were abundant. In a more subtle way, however, success was constructed financially in the strategic change discourse, in common with the wider, dominant discourse. Initial analyses of the market were not made in terms of market structure, competitor analysis, or client segmentation, but in terms of PA's previous, current and projected revenues from each of its main offerings. Conclusions from these analyses focused accordingly on PA's revenue growth prospects, which were taken as the main objective of the strategic change programme. As analysis of internal memos indicated, at the senior management level, the need for strategic change was argued for in terms of market trends, but the focus was on the implications of these trends in terms of PA's revenue performance.

Rationalizations for the strategic change programme thus overwhelmingly rested on financial success and revenue growth. Strategic change was seen as the means to revenue growth, and by implication to financial success, which would in 
turn satisfy all the stakeholders (support staff was not included in the discussion of stakeholders, which referred to clients, consultants and partners of the firm):

Why are we doing this?

... We can only meet these professional and business needs if we grow in profitability to finance the necessary investment. We can only become more profitable if we concentrate on profitable consulting and that requires that we manage ourselves more purposefully ...

The case for change:

Where are we going and why? Our strategic thinking over the last six months has developed to the extent that we know we need to grow ... Revenue growth is the only way to satisfy all our stakeholders ...

Another text indicating financial constructions of success was a forward looking statement written in 1994, and was a description of the ideal future of the organization:

Our culture is dynamic and so are our results. For example, in Europe our operating profit has grown from X million in 1994 to Y million in 1999. Our revenues have grown from $\mathrm{X}$ million to $\mathrm{Y}$ million. What underpins our success?

Thus, financial constructions of success pervaded the strategic change discourse, even though on rare occasions some texts displayed a double-loop awareness that the organization defined success solely in financial terms to the exclusion of other criteria. For example, a document referring to consultant evaluation cautioned that:

Performance management needs to be more complex, to recognize different forms of 'success', but sales and billing still dominates.

Focus on clients. The central theme of clients pervades the strategic change discourse. Clients are constructed as stakeholders 'who need us to grow', as the focus of PA's mission ('we intend to be the premier consultancy for helping clients realize their strategy through people'), or as platforms where the individualistic behaviours of PA consultant were manifested; behaviours that needed to change. The main way in which the client theme is constructed in the strategic change discourse, however, is the need for a more differentiated focus on clients depending on the size of revenue they deliver to PA; and on how to achieve this focus organizationally. Client differentiation was seen as a key lever for change in the early stages of the change process:

(C) Blackwell Publishing Ltd 2006 
Through achieving greater focus on our key clients, rather than dissipating our energy by failing to understand and to provide a service to a vast number of so called client organizations. It will make better commercial sense and it will provide a higher level of service if we can differentiate.

The 'principles underlying the change' were all focused on clients, with the expected outcomes being more 'interesting and profitable business'.

The principles underlying the change should be borne in mind. They are to:

- Give clarity of focus to different kinds of client so that we can waste less time trying to manage them all in the same manner.

- Improve consultant allocation to clients and projects.

- Provide a better offering to our clients.

All of which is designed to increase the amount of interesting and profitable business for us all.

This differentiation of focus depending on the extent of revenue that each client brought to PA was expected to lead to further revenue growth:

To secure the growth we want, and to consult with clients in the way we want to, we must do three clear and straight forward things:

1. Key account focus: . . We will therefore specify and then manage those key accounts that should secure us the largest revenues and most diversified work ...

2. Client service focus: What of the other $\mathrm{X}$ thousand or more clients that PA has in Europe? The more important of these will also be managed by consultants but with a lower priority than the key accounts . . .

3. Expertise management: ...

Clients were segmented in four groups depending on the actual and potential size of revenue that PA earned from them: case accounts, key accounts, medium accounts and small accounts, with the aim of moving clients progressively upwards. This segmentation was expected to lead to higher efficiency of sustaining and growing sales levels:

With a bit of focus like this, $\mathrm{X}$ or so consultants could be sustaining sales levels that it currently takes about (twice $\mathrm{X}$ ) of us to produce ... The aim will be to move clients up through these levels, accepting that sales will fluctuate in the 
Table II. The location of the strategic change discourse in the dominant discourse

\begin{tabular}{lllll}
\hline \hline Enthymeme structure & Discursive example & Nature of statement \\
\hline & $P 1$ & Our key goal is Success & P1 & $\begin{array}{c}\text { Value stating desirable } \\
\text { state of affairs } \\
\text { General belief of } \\
\text { contingent relationship } \\
\text { in normative domain }\end{array}$ \\
General conclusion on \\
required type or class \\
of action
\end{tabular}

short term, and recognizing that it is a dynamic set of relationships with clients moving in both directions.

Sales growth was seen as important enough to have a special project on this area, and to devote an internal 'change bulletin' solely to the progress of this project.

The organizational change process itself was legitimated as worthwhile and important, by allowing consultants working on change projects to charge for their time. In terms of the prevailing reward and evaluation process where charging for one's time (billing to clients) was the key element of success, the organizational change process was now a client! Consultants could then contribute to organizational success by spending time in the interests of the change process, as well as to their individual success within the organization, by contributing to their billing targets. Allowing consultants to charge for their time when working on organizational change projects was symbolically potent because it drew its legitimacy from PA's reward and evaluation system, which embodied the discursive central themes of clients as means to (financial) success.

The strategic change process was thus constructed and legitimated as the means of achieving the ultimate goal of success (constructed financially), through a more effective focus on clients, which would enable higher sales to them. The strategic change theme occupied the place of $\mathrm{Z}$ in the secondary structure, and was legitimated through its conformance to, and co-optation by, the dominant discourse. Table II portrays the location of the strategic change discourse in the dominant discourse.

Thematic unity thus existed not only between the central themes of the dominant discourse (success and clients) but also between these themes and the strategic change theme. The particular form this unity took is a means-ends relationship. In 
the case of the primary structure this relationship is more implicit and located in actors' practical consciousness; in the case of the secondary structure it is more explicit and located in discursive consciousness (Giddens, 1984). The linkage between the two structures $\left(\mathrm{C} 1\right.$ and $\left.\mathrm{P}^{\prime}\right)$ can be seen as an implicit premise, which is close to discursive consciousness but is most often left unstated since it is taken for granted by actors in this social context.

In addition, the means-ends relations involved are those that exist in the interpretive schemes of the actors in that particular context, and not necessarily those which hold more objectively. Rhetorical enthymemes, as Aristotle pointed out, are arguments at a lower level of probability (an apparent or seeming probability) than a logical dialectic (Rhetoric, 1:1:14, 1:2:6). These means-ends relations gain their apparent validity from the particular constructions of central themes in the dominant discourse. For example, if success were not constructed as primarily a financial affair, undertaking a strategic change programme focused on achieving higher sales to clients would not have seemed such an appropriate course of action.

\section{The Marginalized Counter-Discourse}

A counter-discourse is also operating in PA, which does not conform to the discursive structures and constructions of the dominant discourse. It uses different channels, it is concerned with different issues, it has different functions and it derives from a different organizational group. Its relationship with the dominant discourse is one of opposition, albeit weak in extent and consequences. It acts as a coping discourse, helping to safeguard support staff identity against the assaults of the dominant discourse whose constructions of 'success' attribute low status, worth and priority to staff groups that are not in direct contact with clients, and are not seen to contribute to client sales and thus to PA's (financial) success.

The counter-discourse is concerned with commenting on support staff's view of their condition in PA. It is manifested in humorous images and captions sometimes created by support staff themselves, located in their personal space, on the walls in front of their desks and mixed with other images such as photographs of their loved ones and pets, holiday postcards, and functional data such as where the consultants they work with can be found on different days. The counter-discourse does not have any formal means of expression, it is not fixed in text (other than the scattered images in support staff's personal space), it is not a collective, co-ordinated or planned effort, does not contain potent criticism of the dominant group's actions or beliefs, and is certainly not effective in influencing the direction of strategic changes. In all these senses, it was the opposite of the organized resistance through humour that Rodrigues and Collinson (1995) found, which had been effective in a different context.

The counter-discourse shows in a 'humorous' way support staff's reflection on their condition in PA and their dissatisfaction with it, and draws attention to issues support staff are concerned with but have no other means of airing. Several of these 
issues arose in my interviews with support staff during the initial stages of the change process, and were fed back to senior management so that action could be taken to remedy them.

Support staff concerns included not feeling valued in PA, being given low priority, feeling dissatisfied with their salaries which they believed are in the lower quartile in the consulting industry, being expected to work overtime without extra pay (citing PA's inflexible approach to salaries in this regard), having no clear options for career development, and being treated in an inconsiderate and impolite manner by many consultants. In addition, they perceived their work appraisal process as too subjective, without a clear framework, and being based too much on the personal relationship between the support staff and their boss. Commonly used expressions in interviews were that support staff often felt like 'part of the furniture', and were always the 'last to know' about organizational or other changes, even about things that affected them personally. They felt that they didn't know enough about PA's offerings to the market, and how their work fits in or contributes to these offerings. Support staff perceived a divide between them and consultants, a 'them and us' situation. Many members of this group also wondered why their suggestions to senior management were never implemented or even taken seriously.

Vivid examples of consultants' inconsiderate treatment of support staff, for example, were given in the mock trial of the imaginary PA consultant that I had observed. After the charge was read, the first witness for the prosecution gave a damning testimony, describing an incident where a consultant gave her work without explaining clearly how it should be done. Then, the consultant wanted a changed version 'for no good reason', and 'couldn't understand how long it would take to redo' (half a day in the secretary's estimation); he then didn't even say thank you when the revised work was delivered. The second witness gave a similar testimony. A client had phoned up wanting the consultant's report for use in a meeting. The secretary 'covered up' for the consultant who was not around, and when he returned, he wanted the work done there and then, not realizing that the secretary had also other consultants' work to do. Even though she explained, the consultant didn't understand.

Support staff in interviews mentioned examples of not only consultants' but also management's actions that they saw as telling of management's attitude toward them. One such example that left a deep impression on a secretary occurred during her annual meeting with her boss to discuss her performance review. During the review a consultant walked in the office wanting to speak to her boss about a client project. The boss immediately interrupted the review to speak to the consultant. To the secretary, her boss's response was a potent symbolic indication that the boss did not value her very much, since he was willing to interrupt their most important wannual meeting, to speak with someone who came in un-announced and without an appointment, about something that in her view could have waited until after the review meeting was finished.

C Blackwell Publishing Ltd 2006 
Later interviews and informal conversations with support staff, as well as company-wide surveys I conducted, revealed that the change process did not address their concerns, contrary to consultants' concerns which were being addressed through the institution of internal projects focused on these concerns. Even though dominant groups expressed their desire to get feedback on support staff concerns, and said that these were as important as consultant concerns, their actions and the allocation of resources indicated that support staff concerns were of low priority.

The third survey I conducted, for example, in February 1996, validated interview and informant data by showing that only 3 per cent of support staff felt that the following concerns expressed around one and a half year earlier had been addressed: not feeling valued in PA (own ideas do not count, last to find out about things, insufficient and inflexible financial arrangements); inconsiderate treatment by consultants (poor workload planning, unclear accountabilities for resolving support staff concerns) and work appraisal (no clear framework, too subjective). Even less than that, 0 per cent felt that the following concerns were addressed: insufficient knowledge of PA's offerings and how support staff contributes; and absence of clear options for career development.

The criticism of the dominant groups that the counter-discourse employs is of a kind legitimated by wider social conventions: satire. The penetration of this counter-discourse in the formal expressions of the dominant discourse, however, is negligible. The prominent monthly internal publication read by almost everyone, for example, is an instrument of the dominant discourse. Contributions of support staff in this publication are rare, involving mostly one's introduction to the rest of the organization when joining PA. There are no internal publications dedicated to support staff.

The satirical images used in the counter-discourse are both general, for example humorously portraying professionally abused secretaries, or portraying executives as egoistic and greedy, as well as specific to the particular situation of support staff. The themes of the more specific images are consistent with several of the concerns expressed by support staff in interviews. For example, there was an image of $\mathrm{Mr}$ Blobby saying: 'Blobby blobby blob! (Translation: I'm here to tell you about your pay rise!) Enough said.' A second image of a dark tunnel had the following caption: 'Due to current financial constraints the light at the end of the tunnel will be switched off'. Another image showed an oppressed secretary literally under a huge thumb. Lastly, another image showed a boss feeling distressed with work at 5:30 pm, but with no apparent consideration for his secretary who is expected to work overtime without extra pay, who has huge piles of work at her desk and appears to want to go home.

It is interesting that management, the target of the satire, could see these images and identify the people who display them. In this sense humour and satire are more than 'symbolic cloaks' which minimize the risk of managerial reprisals (Rodrigues 
and Collinson, 1995). In PA's case, they are openly used by identifiable individuals to express their task-related concerns and their views on their condition in the organization. From a functionalist perspective of humour as a safety valve, the existence and content of this counter-discourse may be tacitly 'accepted' by management because it functions as a steam-letting device, helping to enable the existing system and distribution of authority and resources to keep functioning without substantial disruptions. Another potential explanation for management's tacit 'acceptance' through non-confrontation, may be that satire, a key discursive element of PA's counter-discourse is an indirect and subtle form of critique, a world apart from management's dominant discourse characterized by normative rationality, instrumentality and teleology. The dominant discourse was thus faced with a different world, one it did not feel inclined or willing to engage with.

\section{DISGUSSION AND IMPLIGATIONS}

\section{Modes of Discourse and Inter-Discursive Relationships}

The aims of this research were firstly to understand in what sense we can speak of 'modes of discourse' in organizational settings; secondly to explore the potential existence and nature of interrelations among different modes of discourse; and thirdly to explore the constructive potential of modes of discourse on their social and organizational contexts. Through shedding light on these questions, this research has aimed to respond to calls for greater clarity in the specification of the concept of discourse, as well as a deeper understanding of the constructive effects of discourse in social organizations (Grant et al., 2001; Keenoy et al., 1997; van Dijk, 1997).

This study has revealed an organizational field wherein a dominant mode of discourse forms an overarching structure where other discourses must be located if they are to be taken seriously by those in power and by the members of the dominant sub-culture. The findings suggest that one potentially useful interpretation of the nature of 'modes' of discourse, is that they are constituted of rhetorical enthymemes; of interrelated primary and secondary argument structures that enshrine the central themes of the discourse in terms of means-ends relationships, and which have both normative and positive effects on their social context. The secondary enthymeme structure is flexible in terms of content so that themes relating to situational exigencies can be located. Any additional themes that are located in this flexible secondary structure for the purposes of legitimation must also be co-opted in the existing means-ends relationships of the dominant discourse, if they are to be taken seriously by those in power and those aligned with the powerful. The secondary structure thus functions at the positive, action domain, and is located in actors' discursive consciousness; whereas the primary structure functions in the normative domain and is located in actors' practical consciousness. 
Analysis of the strategic change discourse exemplifies the process of locating a situational theme in the secondary structure so that in this case the necessity and extent of strategic change argued for could be legitimated. The strategic change theme was linked argumentatively with the central themes of the dominant discourse, and was consistent with their specific constructions. The strategic change discourse was thus subservient to, and located in, the dominant discourse.

The strategic change discourse also illustrates the existence of a wider rhetorical strategy in PA, which provides rules for 'proper' argumentation in that context. This strategy has to be followed by actors in that context if they are to be taken seriously and is manifested in individual texts produced by different speakers or authors, discoursing about different issues, at different points in time and in different situations. The rhetorical strategy involved certain 'rules' for 'proper' argumentation in this social context, which are: Firstly, to legitimate a certain course of action or inaction, locate it in the structures and constructions of the dominant discourse. Secondly, this can be done through implicit or explicit reference to its contributions to success and to its effects on clients. Thirdly, follow the particular constructions of these central themes in the dominant discourse; for example, talk of financial success and adding value or selling more to clients. Fourthly, use both the vocabulary and style of the dominant discourse (in terms of style, your own texts should be imbued with teleology, instrumentality, and measurability).

Table III portrays key features of the three discourses in relation to each other.

This study therefore shows that discourses are not autonomous but linked with other discourses in cooperative or antagonistic ways (see Palmer and Dunford (2002) for an extended discussion of the various potential relationships among discourses). PA's dominant discourse draws from wider contextual discourses, especially what du Gay and Salaman (1992) have referred to as the discourse of enterprise, emphasizing the 'sovereign consumer' as the basis of organizational arrangements, as well as industry-wide concerns with 'adding value' (Chatman and Jehn, 1994). The relationship between the dominant and the strategic change discourses in PA shows how one newly established, situationally prompted and temporary body of discourse can draw from the structures and constructions of an overarching discourse; and how, in doing so, it seeks to legitimize itself and certain courses of action or inaction.

\section{Discursive Antagonisms between the Dominant and Counter-Discourse}

The analysis of PA's discourses has revealed a complex picture of the rule of a dominant discourse that is relatively stable at the structural level but flexible at the communicative action level where other discourses can be located (such as the strategic change discourse). It has also revealed the existence of a counter-discourse 
Table III. Features of the dominant, strategic change and counter discourse

\begin{tabular}{|c|c|c|c|}
\hline Features & Dominant discourse & Strategic change discourse & Counter-discourse \\
\hline $\begin{array}{l}\text { Discursive } \\
\text { elements }\end{array}$ & $\begin{array}{l}\text { Enthymeme structures, } \\
\text { central themes, specific } \\
\text { constructions }\end{array}$ & $\begin{array}{l}\text { Themes legitimated } \\
\text { through the dominant } \\
\text { discourse }\end{array}$ & $\begin{array}{l}\text { Satirical images and } \\
\text { captions }\end{array}$ \\
\hline $\begin{array}{r}\text { Channels of } \\
\text { expression }\end{array}$ & Formal, extensive & Formal, extensive, & Informal, scattered \\
\hline Time scale & Long-term & Temporary & Long-term \\
\hline Orientation & $\begin{array}{l}\text { Normative, instrumental, } \\
\text { teleological }\end{array}$ & Action-oriented & $\begin{array}{l}\text { Resistance through } \\
\text { humor }\end{array}$ \\
\hline $\begin{array}{l}\text { Functions } \\
\text { in social } \\
\text { context }\end{array}$ & $\begin{array}{l}\text { Communicative: } \\
\text { Informing, } \\
\text { co-ordinating, } \\
\text { persuading. } \\
\text { Constructive: Defining } \\
\text { criteria of 'success', } \\
\text { allocating worth and } \\
\text { value to org groups by } \\
\text { reference to these } \\
\text { criteria }\end{array}$ & $\begin{array}{l}\text { Enabling organizational } \\
\text { responsiveness to } \\
\text { competitive demands, } \\
\text { within lense of } \\
\text { dominant discourse }\end{array}$ & $\begin{array}{l}\text { Expressing } \\
\text { dis-satisfaction, letting } \\
\text { off steam, safeguarding } \\
\text { identity and self-worth }\end{array}$ \\
\hline
\end{tabular}

that lies outside the dominant themes and constructions of the dominant discourse, in this sense lending support to a dialogical rather than monological perspective on organizational discourse (Boje, 1995; Grant et al., 1998; Keenoy et al., 1997). This analysis has also aimed to address both the interpretive aim of understanding agents' worlds, as well as a critical concern with the effects of dominant discourses on disadvantaged groups (Mumby and Clair, 1997; Oswick et al., 1997).

In this vein, an antagonistic relationship between the dominant and counterdiscourses can be discerned, where the counter-discourse is shaped by what it opposes, being positioned against the central themes and constructions of the dominant discourse and its effects. In terms of its themes and constructions, the counter-discourse does not draw from the dominant discourse for legitimation, because the very nature of the dominant discourse places support staff, the originators and consumers of the counter-discourse, in a disadvantaged position. Support staff receives low priority, as ethnographic data have shown over and over again, partly because of the nature and effects of the dominant discourse that stresses financial success, adding value and achieving increased sales to clients. In terms of its existence, however, the counter-discourse is made possible by the effects of the very discourse it opposes.

From an organizational analysis perspective, this situation illustrates the argument that groups that can effectively enable the organization to respond to crucial contingencies have higher intra-organizational power (Hickson et al., 1971). In this 
case, PA's dominant discourse defines the perceived organizational contingencies and then attributes worth and power to those who can respond to these contingencies, the consulting staff.

From a critical perspective however, the antagonism between the dominant and counter-discourses, the weak resistance of the counter-discourse and the overarching effects of the dominant discourse are all illustrations of Foucault's view, drawing from Nietzsche, of discourses as the 'will to power', or Habermas' thesis that 'knowledge-constituting interests take form in the medium of work, language and power' (1987, p. 313). Foucault, for example, suggested that 'pure' or 'value-free' knowledge was not possible because knowledge is subordinated to selfish interests and power relations (Foucault, 1977a, 1977b). In this sense knowledge, and discourses portraying and producing such knowledge are by no means neutral or objective, but inherently and surreptitiously biased in favour of dominant interests, in this case illustrated by the nature and effects of the dominant discourse.

Power for Foucault, however, was not simply repressive, but had positive, productive, and seductive effects. People, in other words, may not simply feel dominated by power, but could be attracted to it and its effects such as the subjective identities it can offer through discourse (1977b, p. 119). In PA, for example, the constructive effects of the dominant discourse were desirable and attractive to both new consulting recruits and seasoned consultants, who enjoyed their consulting identity and the empowerment, status and autonomy that went with it. Many employees in the surveys and IT departments were also acutely drawn to the effects of the dominant discourse, seduced by the consulting identity, and aspiring to become consultants in future. The creation of an overarching discourse with pervasive themes and specific constructions in PA, as well as the projection of a seductive consulting identity, is a prime example of the exercise of power through concertive control (Tompkins and Cheney, 1985).

Support staff, on the other hand, perceived that they had no chance of ever becoming consultants, and feeling suffocated by the dominant discourse and its effects, were attempting to safeguard their identity and sense of self-worth through producing, and participating in, a courageous but weak counter-discourse. Is there leeway for the dominant and counter-discourses to communicate within a context of constructive and co-operative dialogical exchange, for example through the method of Socratic dialogue (Bolten, 2001)? An effective dialogical exchange presupposes that the parties want to speak to each other, have a genuine interest in what each party is saying, and want to find common ground. While from a pluralist perspective (Morgan, 1986) this would be both possible and desirable, from a critical perspective a productive dialogue would seem unlikely. From a critical perspective the dice are already loaded; this discursive antagonism is imbued with power imbalances and surrounded by an ideology enshrined in the dominant discourse (Habermas, 1987, p. 311), that rationalizes and perpetuates existing power arrangements and attributions of worth. 


\section{Structural Discursive Features as Constructive of Social Reality}

The potency of discourse to affect organizational processes and outcomes is well accepted (e.g. Harley and Hardy, 2004; Maitlis and Lawrence, 2003; Palmer and Dunford, 2002; Vaara et al., 2004), and one of this study's aims has been to gain a deeper understanding of this constructive potential. One finding is that the constructive potential of discourse is based primarily on its deeper structures, and on the consonance of surface (communicative) actions with these structures.

PA's enthymeme structures and central themes illustrate empirically the nature of structural features of discourse. Within particular social contexts, these features transcend individual texts, manifesting in a variety of situations and at different times. They are most often assumed and implicit rather than explicitly stated (Heracleous and Hendry, 2000). This research shows that discursive structures and constructions can be potent in constructing social reality in the following ways. Firstly, they persist in the longer term and reside in actors' practical consciousness, informing their interpretations and actions. As was discussed in the section on 'field analysis: discourses of people associates', the central themes and constructions of the discourse were continually and recursively manifesting in agents' actions, as well as organizational processes such as the reward and evaluation system and the internal market for consulting talent. Secondly, discursive structures and constructions (acting as implicit premises in organizational enthymemes) are inculcated in agents through socialization and experience in particular contexts, in the same way as cultural values and beliefs (but they are different from cultural values and beliefs, however, in the sense that they can be seen as perceptions of implicit means-ends relationships). Thirdly, discursive central themes and their constructions take on the properties of normative devices for orienting action, where action is itself a symbolic affirmation (or potentially challenge) of the importance of these themes, as was shown above.

Conversely to field data that that have shown tight consonances between discursive structures and constructions as discussed above, field data have also shown that if there are communicative actions that do not agree with the dominant discourse, such statements are not potent in constructing social reality. For example, the MD addressed the organization in a 1994 speech, and characterized all groups, including support staff, as stakeholders in the business in order to encourage them to identify with the future of PA and to motivate them to change. Such comments were partly prompted by my earlier feedback to senior management that both consulting and support staff had certain concerns about the change process and more generally about the organization, and on the compelling effect of this data on a newly appointed MD to show concern for all groups in the organization. The MD's statements could not change the fact, however, that consultants get a much larger profit share and higher priority than non-consulting staff, and everyone knew that the most significant financial stakeholders were the partners 
who own PA. The MD's statements, therefore, were not potent in influencing social reality because of two main factors: firstly, their disagreement with the structures and constructions of the dominant discourse; and secondly, the existence of contextual, extra-discursive conditions which also defined which stakeholder groups were seen as more important.

In sum, this research has shown that modes of discourse can be usefully conceptualized as rhetorical enthymemes constituted of relatively stable, normative structures and flexible, action-oriented structures; secondly, that modes of discourse can interrelate through their deeper structural features, and can have mutually co-optive or antagonistic relationships; and lastly that the constructive potential of discourse is based primarily on its deeper structures, and on the consonance of surface (communicative) actions with these structures.

\section{NOTE}

*The author would like to thank the General Editor, Timothy Clark, and the three anonymous reviewers for their constructive comments on earlier versions of the manuscript.

\section{REFERENCES}

Aristotle (1991). On Rhetoric. Translated by G. A. Kennedy Oxford: Oxford University Press.

Austin, J. L. (1961). How To Do Things With Words. Oxford: Oxford University Press.

Barley, S. R. and Tolbert, P. S. (1997). 'Institutionalization and structuration: studying the links between action and institution'. Organization Studies, 18, 93-117.

Barry, D. and Elmes, M. (1997). 'Strategy retold: toward a narrative view of strategic discourse'. Academy of Management Review, 22, 429-52.

Berger, P. and Luckmann, T. (1966). The Social Construction of Reality. London: Penguin.

Boje, D. M. (1991). 'The storytelling organization: a study of story performance in an office-supply firm'. Administrative Science Quarterly, 36, 106-26.

Boje, D. M. (1995). 'Stories of the storytelling organization: a postmodern analysis of Disney as Tamara-land'. Academy of Management fournal, 38, 997-1035.

Bolten, H. (2001). 'Managers develop moral accountability: the impact of Socratic dialogue'. Reason in Practice, 1, 3, 21-34.

Chatman, J. A. and Jehn, K. A. (1994). 'Assessing the relationship between industry characteristics and organizational culture: how different can you be?'. Academy of Management Fournal, 37, 522-53.

Cheney, G. and McMillan, J. J. (1990). 'Organizational rhetoric and the practice of criticism'. Fournal of Applied Communication Research, 18, 2, 93-114.

Cheney, G., Christensen, L. T., Conrad, C. and Lair, D. J. (2004). 'Corporate rhetoric as organizational discourse'. In Grant, D., Hardy, C., Oswick, C., Phillips, N. and Putnam, L. L. (Eds), Handbook of Organizational Discourse. London: Sage, 79-103.

Cicourel, A. V. (1981). 'Three models of discourse analysis: the role of social structure'. Discourse Processes, 3, 101-31.

de Vries, K., Manfred, F. R. and Miller, D. (1987). 'Interpreting organizational texts'. Fournal of Management Studies, 24, 233-47.

du Gay, P. and Salaman, G. (1992). 'The cult(ure) of the customer'. Fournal of Management Studies, 29, 615-33.

Eisenhardt, K. M. (1989). 'Building theories from case study research'. Academy of Management Review, 14, 532-50.

Eemeren, F. H., Grootendorst, R., Jackson, S. and Jacobs, S. (1997). 'Argumentation'. In van Dijk, T. A. (Ed.), Discourse Studies: A Multidisciplinary Introduction, Vol. 1. Thousand Oaks, CA: Sage, 208-29. 
Fairclough, N. (1992). 'Discourse and text: linguistic and intertextual analysis within discourse analysis'. Discourse and Society, 3,193-217.

Fisher, A. (1988). The Logic of Real Arguments. Cambridge: Cambridge University Press.

Foucault, M. (1972). The Archaeology of Knowledge. London: Routledge.

Foucault, M. (1977a). 'History of systems of thought'. In Bouchard, D. (Ed.), Language, Counter-Memory, Practice: Selected Essays and Interviewes by Michel Foucault. Ithaca, NY: Cornell University Press, 199-204.

Foucault, M. (1977b). Discipline and Punish. London: Penguin.

Gadamer, H-G. (1997). 'Rhetoric and hermeneutics'. In Jost, W. and Hyde, M. J. (Eds), Rhetoric and Hermeneutics in Our Time: A Reader. New Haven, CT: Yale University Press, 45-59.

Geertz, C. (1973). The Interpretation of Cultures. New York: Basic Books.

Giddens, A. (1979). Central Problems in Social Theory. London: Macmillan.

Giddens, A. (1984). The Constitution of Society. Cambridge: Polity Press.

Giddens, A. (1987). Social Theory and Modern Sociology. Cambridge: Polity Press.

Giddens, A. (1993). New Rules of Sociological Method, 2nd edition. Stanford, CA: Stanford University Press.

Gill, A. M. and Whedbee, K. (1997). 'Rhetoric'. In van Dijk, A. (Ed.), Discourse Studies: A Multidisciplinary Introduction, Volume 1. Thousand Oaks, CA: Sage, 157-83.

Gowler, D. and Legge, K. (1983). 'The meaning of management and the management of meaning'. In Earl, M. (Ed.), Perspectives in Management. Oxford: Oxford University Press, 197-233.

Grant, D., Keenoy, T. and Oswick, C. (1998). 'Organizational discourse: of diversity, dichotomy and multi-disciplinarity'. In Grant, D., Keenoy, T. and Oswick, C. (Eds), Discourse and Organization. London: Sage, 1-13.

Grant, D., Keenoy, T. and Oswick, C. (2001). 'Organizational discourse: key contributions and challenges'. International Studies of Management and Organization, 31, 3, 5-24.

Habermas, J. (1984). The Theory of Communicative Action, Volume 1. Boston, MA: Beacon Press.

Habermas, J. (1987). Knowledge and Human Interests. Cambridge: Polity Press.

Hammersley, M. and Atkinson, P. (1995). Ethnography: Principles in Practice, 2nd edition. London: Routledge.

Harley, B. and Hardy, C. (2004). 'Firing blanks? An analysis of discursive struggle in HRM'. Fournal of Management Studies, 41, 3, 377-400.

Heracleous, L. and Barrett, M. (2001). 'Organizational change as discourse: communicative actions and deep structures in the context of information technology implementation'. Academy of Management Fournal, 44, 755-78.

Heracleous, L. and Hendry, J. (2000). 'Discourse and the study of organization: towards a structurational perspective'. Human Relations, 53, 1251-86.

Hickson, D. J., Hinings, C. R., Lee, C. A., Schneck, R. E. and Pennings, J. M. (1971). 'A strategic contingencies theory of intra-organizational power'. Administrative Science Quarterly, 16, 216-29.

Jacobs, C. and Heracleous, L. (2001). 'Seeing without being seen: towards an archaeology of controlling science'. International Studies of Management and Organization, 31, 3, 113-35.

Keenoy, T., Oswick, C. and Grant, D. (1997). 'Organizational discourses: text and context'. Organization, 4, 147-57.

Maitlis, S. and Lawrence, T. B. (2003). 'Orchestral man - oeuvres in the dark: understanding failure in organizational strategizing'. Fournal of Management Studies, 40, 109-39.

Morgan, G. (1986). Images of Organization. Beverly Hills, CA: Sage.

Mumby, D. K. and Clair, R. P. (1997). 'Organizational discourse'. In van Dijk, T. A. (Ed.), Discourse as Social Interaction. London: Sage, 181-205.

Oswick, C., Keenoy, T. and Grant, D. (1997). 'Managerial discourses: words speak louder than actions?'. Fournal of Applied Management Studies, 6, 5-12.

Palmer, R. E. (1969). Hermeneutics. Evanston, IL: Northwestern University Press.

Palmer, R. E. (1997). 'What hermeneutics can offer rhetoric'. In Jost, W. and Hyde, M.J. (Eds), Rhetoric and Hermeneutics in Our Time: A Reader. New Haven, CT: Yale University Press, 108-31.

Palmer, I. and Dunford, R. (2002). 'Managing discursive tension: the co-existence of individualist and collaborative discourses in Flight Centre'. Fournal of Management Studies, 39, 1045-69.

Phillips, N. and Brown, J. L. (1993). 'Analyzing communication in and around organizations: a critical hermeneutic approach'. Academy of Management Fournal, 36, 1547-76.

Ricoeur, P. (1971a). 'The model of the text: meaningful action considered as a text'. Social Research, 38, $529-62$. 
Ricoeur, P. (1971b). 'What is a text? Explanation and understanding'. In Rasmussen, D. (Ed.), Mythic-Symbolic Language and Philosophical Anthropology. The Hague: Martinus Nijhoff, 135-50.

Ricoeur, P. (1973a). 'The task of hermeneutics'. Philosophy Today, 17, 112-28.

Ricoeur, P. (1973b). 'The hermeneutical function of distantiation'. Philosophy Today, 17, 129-41.

Ricoeur, P. (1983). 'On interpretation'. In Montefiore, A. (Ed.), Philosophy in France Today. New York: Cambridge University Press, 175-97.

Ricoeur, P. (1997). 'Rhetoric-poetics-hermeneutics'. In Jost, W. and Hyde, M. J. (Eds), Rhetoric and Hermeneutics in Our Time: A Reader. New Haven, CT: Yale University Press, 60-72.

Rodrigues, S. B. and Collinson, D. L. (1995). " "Having fun?" Humor as resistance in Brazil'. Organization Studies, 16, 739-68.

Schein, E. (1987a). Process Consultation, Volume 2. Reading, MA: Addison-Wesley.

Schein, E. (1987b). The Clinical Perspective in Fieldwork. Qualitative Research Methods. Beverly Hills, CA: Sage.

Schein, E. (1992). Organizational Culture and Leadership, 2nd edition. San Francisco, CA: Josey-Bass.

Thachankary, T. (1992). 'Organizations as "texts": hermeneutics as a model for understanding organizational change'. Research in Organization Change and Development, 6, 197-233.

Tomkpins, P. K. and Cheney, G. (1985). 'Communication and unobtrusive control in contemporary organizations'. In McPhee, R. D. and Tompkins, P. K. (Eds), Organizational Communication: Traditional Themes and New Directions. Beverly Hills CA: Sage, 179-210.

Vaara, E., Kleymann, B. and Seristo, H. (2004). 'Strategies as discursive constructions: the case of airline alliances'. Fournal of Management Studies, 41, 1, 1-35.

van Dijk, T. A. (1997). 'The study of discourse'. In van Dijk, T. A. (Ed.), Discourse Studies: A Multidisciplinary Introduction, Volume 1. Beverly Hills, CA: Sage, 1-34.

Van Maanen, J. (1979). 'The fact of fiction in organizational ethnography'. Administrative Science Ouarterly, 24, 539-50.

Weaver, G. R. and Gioia, D. A. (1994). 'Paradigms lost: incommensurability vs structurationist inquiry'. Organization Studies, 15, 565-90.

Wilkins, A. and Ouchi, W. (1983). 'Efficient cultures: exploring the relationship between culture and organizational performance'. Administrative Science Quarterly, 28, 468-81. 